\title{
LA CONSTRUCCIÓN NAVAL ESPAÑOLA EN EL PACÍFICO SUR: EXPLOTACIÓN LABORAL, RECURSOS MADEREROS Y TRANSFERENCIA INDUSTRIAL ENTRE NUEVA ESPAÑA, FILIPINAS, INDIA Y CAMBOYA (SIGLOS XVI Y XVII)
}

\section{Resource Mobilization for Spanish Naval shipbuilding in the South Pacific: New Spain, Philippines, India and Cambodia (sixteenth to seventeenth centuries)}

\section{Iván VALDEZ-BUBNOV}

Instituto de Investigaciones Históricas

Universidad Nacional autónoma de México

ivanvaldezbubnov@yahoo.com

Fecha de recepción: 21/10/2020

Fecha de aceptación: 03/06/2021

RESUMEN: El presente estudio tiene por objetivo ofrecer una interpretación estructural del funcionamiento de la industria de construcción naval española en el sureste asiático, desde la perspectiva específica del uso de sus recursos madereros y su vínculo con la explotación del trabajo indígena, así como comprender las causas de la progresiva transferencia de esta industria, desde los astilleros americanos a las islas Filipinas y, posteriormente, también a otras regiones del Pacífico sur. Estos propósitos intersectan con otros temas estructurales, directamente vinculados con la industria de construcción naval en Filipinas y con el régimen establecido por la administración española para la explotación de sus recursos forestales: la estructura administrativa, civil y religiosa del establecimiento hispano en ese archipiélago, su vinculación con las reducciones a poblado de sus habitantes,

Ediciones Universidad de Salamanca / అ@@ Stud. his., H. ${ }^{a}$ mod., 43, n. 1 (2021), pp. 71-102 
y las diversas tentativas, tanto teóricas como prácticas, por integrarlo más profundamente en las estructuras políticas y mercantiles del Pacífico sur.

Palabras clave: construcción naval española; Filipinas; Camboya; Siam; Pacífico hispano; recursos forestales.

ABSTRACT: The purpose of ths article is to understand the functioning of the Spanish shipbuilding industry in South East Asia, from the perspective of the exploitation of timber resources and indigenous labour. It also aims at understanding the causes of the transfer of this industry from the Pacific coasts of New Spain, where it was based during most of the sixteenth century, to the Philippine islands and, later on, to other regions of South East Asia. It describes the administrative stucture of the Spanish settlment in the Philippine islands from the perspective of the administration of its human and timber resuources, as well as its the relationship of the shipbuilding industry with the projects for further Spanish expansion into China, Cambodia and Siam.

Keywords: Spanish naval shipbuilding; Philippines; Cambodia; Siam; Spanish Pacific; timber resources.

\section{INTRODUCCIÓN}

El presente estudio tiene dos propósitos. El primero es ofrecer una interpretación estructural del funcionamiento de la industria de construcción naval española en el sureste asiático, desde la perspectiva específica del uso de sus recursos madereros, así como su vínculo con la explotación del trabajo indígena. El segundo objetivo se deriva directamente del primero, y consiste en comprender las causas de la progresiva transferencia de esta industria, desde los astilleros americanos (en los cuales estuvo basada durante la mayor parte del siglo XVI), a las islas Filipinas y, posteriormente, también a otras regiones del Pacífico sur, en la forma de diversos proyectos de éxito relativo. Estos propósitos intersectan con otros temas directamente vinculados con la industria de construcción naval en Filipinas y con el régimen establecido por la administración española para la explotación de sus recursos forestales: la estructura administrativa, civil y religiosa del establecimiento hispano en ese archipiélago, su vinculación con las reducciones a poblado de sus habitantes, y las diversas tentativas, tanto teóricas como prácticas, por integrarlo más profundamente en las estructuras políticas y mercantiles del Pacífico sur. En este sentido, el presente estudio busca vincular la interpretación del funcionamiento de la industria de construcción naval 
española en Asia, en sus dimensiones político-administrativa, maderera y laboral, con los proyectos concebidos para la conquista de China y, posteriormente, para la transferencia de esa industria, desde Filipinas, a la India, Camboya y Siam. Esta vinculación temática se encuentra basada, tanto en las conclusiones de la historiografía reciente y contemporánea sobre la naturaleza de la presencia española en Asía, como de las últimas investigaciones sobre la construcción naval en esa región, así como en datos específicos presentes en las obras de los cronistas del Pacífico hispano, y en fuentes documentales hasta el momento inéditas.

\section{LA PRIMERA EXPANSIÓN HISPANA EN EL PACÍFICO SUR Y LOS PRIMEROS EJEMPLOS DE CONSTRUCCIÓN NAVAL ESPAÑOLA EN ASIA}

La colonización española de América fue posible, en una gran medida, debido al establecimiento de diversos astilleros en las Antillas, Nueva España, Castilla del Oro, y el Perú, los cuales produjeron los navíos necesarios, no solamente para las diversas expediciones de exploración y conquista de los imperios indígenas, sino también de las costas de la entonces llamada Mar del Sur, donde se desarrolló gradualmente un comercio incipiente entre los nacientes virreinatos regidos desde la Ciudad de México y Lima (Borah, 1954; Brand, 1956; Radell, 1971, Clayton, 1975). Por otra parte, la exploración gradual de las rutas del océano Pacífico, iniciada de manera prácticamente paralela a estos procesos, fue resultado de una serie de esfuerzos por alcanzar las islas de la Especiería y las economías desarrolladas del sureste asiático (Martínez Shaw, 2001). Estos esfuerzos, sin embargo, fueron realizados tras la expansión de los portugueses por la ruta del Cabo de Buena Esperanza y el océano índico (Subrahmanyam, 2007), a través de la cual habían establecido enclaves en Calicut, y Cochin, entre 1502 y 1504; Goa, en 1510; Malaca, en 1511; las Molucas, en 1512; Cantón, en 1517, y Siam, en 1518.

Aunque las dos primeras expediciones transpacíficas que partieron desde España en este período (Fernando de Magallanes, 1519-22; y García Jofre de Loaysa, 152527)- fueron realizadas con navíos construidos en los tradicionales astilleros del Cantábrico, las «armadas de la especiería» que les sucedieron - comandadas por Álvaro de Saavedra Cerón (1527), Hernando de Grijalva (1537) y Ruy López de Villalobos (1542) - utilizaron navíos construidos en América central. Los astilleros novohispanos, por su parte, hicieron posible la planeación de las expediciones de Simón de Alcazaba y Pedro de Alvarado hacia las costas del septentrión novohispano, así como el armamento de las cuatro expediciones enviadas por Hernán Cortés a esa región entre 1532 y 1539 (León-Portilla, 1985). Finalmente, el astillero de Barra de Navidad, al norte de Acapulco, botó al agua los navíos que fueron utilizados por la expedición de Legazpi-Urdaneta, la cual condujo al descubrimiento del tornaviaje 

RECURSOS MADEREROS Y TRANSFERENCIA INDUSTRIAL ENTRE NUEVA ESPAÑA...

entre Cebú y Acapulco, en 1565 y, con ello, a los primeros pasos de la ocupación española de Filipinas, así como al establecimiento de la ruta transpacífica (Pizano y Saucedo, 1964; García-Abasolo, 1982; Machuca, 2009; Pinzón, 2014: 72-73).

La necesidad de establecer una infraestructura de construcción y mantenimiento de buques en las islas del Pacífico sur, independiente de los recursos americanos, fue evidente para los observadores españoles prácticamente desde el inicio de este ciclo de exploraciones. Los primeros cronistas de este proceso - Antonio de Pigafetta (1519-1522), García de Escalante Alvarado (1542), y Juan de la Isla (1564) - llamaron la atención a los recursos madereros de las Molucas y las Islas del Poniente, mientras que Gonzalo Fernández de Oviedo (1557), describió con detalle la construcción naval indígena, así como la notable pericia de sus poblaciones marineras. Así, se ha precisado que los primeros ejemplos de construcción naval en esa región se remontan a fines de la década de 1520, en las Molucas, como resultado de la expedición de Loaysa; de 1540, como resultado de la expedición de Villalobos; y a mediados de la década de 1560, en las Visayas, como parte de las campañas de Miguel López de Legazpi en la isla de Cebú, (Amaya, 2017; Rodríguez Castillo, 2017; ValdezBubnov, 2017). Es preciso considerar también las embarcaciones construidas para las primeras expediciones a Mindanao, en 1576, o las cuatro galeras y tres galeotas, destinadas a la expedición de Borneo de 1577, donde se fabricaron otras más en 1578 (Mallari, 1989; Valdez-Bubnov, 2019a).

Fue tan solo a partir de 1566, que el establecimiento de una infraestructura de construcción naval permanente comenzó a ser considerada como un imperativo para la presencia española en Asia. El galeón San Jerónimo arribó a Cebú, proveniente de Acapulco, en octubre de ese año, transportando pertrechos para la conquista, pero llegó tan comido de broma que no pudo efectuar el tornaviaje a causa del lamentable estado de su quilla y tracas (Peterson, 2014: 79). Tras este episodio, en 1568, Legazpi escribió a Felipe II, describiendo la riqueza de los recursos madereros de Filipinas y enfatizando la necesidad e importancia de establecer astilleros permanentes en esas islas (Bankoff, 2004: 321; Wing, 2015: 113). La respuesta llegó en 1572, en la forma de una armada de socorro enviada desde Sevilla con una remesa de insumos náuticos y de calafateo, bajo el mando de Antonio de La Torre (Sales-Colin, 2011: 60). Entre ese mismo año, Legazpi transfirió el centro de gravedad de la ocupación española desde Cebú a Luzón, con la conquista de la bahía de Manila. Este cambio reflejó, según la historiografía reciente, el interés por acceder al comercio con China, en contraste con la orientación inicial de competir con los portugueses en las Molucas por el tráfico de especias (Ollé, 2002; Cervera, 2013 y 2016). Durante los dos años siguientes, la corona expidió las primeras instrucciones de navegación y comercio con Acapulco, las cuales no solamente formalizaron los procedimientos mercantiles de esa ruta, sino también el número de navíos en servicio, y la financiación de sus fábricas por parte de la tesorería de Manila. Esta dependía, a su vez, de remesas en metálico y en 

RECURSOS MADEREROS Y TRANSFERENCIA INDUSTRIAL ENTRE NUEVA ESPAÑA...

especie, enviadas desde Nueva España bajo el nombre genérico de situado (Yuste, 1984, Sluiter, 1998; Subrahmanyam, 2007). Estas medidas, sin embargo, no representaron el establecimiento inmediato de una nueva infraestructura permanente de construcción naval en Filipinas, sino meramente de mantenimiento y reparación para los navíos en tornaviaje, y en servicio del incipiente comercio regional.

Además de la plata americana y los insumos transportados directamente desde Europa, por el cabo de Buena Esperanza, o a través del eje Veracruz-Acapulco en conexión con la naciente ruta transpacífica, es preciso considerar dos elementos decisivos para el origen y el funcionamiento de la industria de la construcción naval española en Asia, en esta etapa inicial. El primero de estos elementos fue la importante presencia de comunidades extranjeras en Luzón, sobre todo chinas y japonesas, que precedían al asentamiento hispano en Manila (Iaccarino, 2011: 99-100). Estas comunidades actuaban como representantes del comercio de exportación de sus respectivas regiones de origen, pero, también, como una fuerza de trabajo especializada en la producción de diversos insumos industriales de alta calidad, especialmente manufacturas de hierro, pero también plomo, azufre, pólvora, salitre, y otras (García-Abasolo, 2011, 2013, 2017). Desde esta etapa fundacional, el gobierno de Manila buscó expresamente sustituir del todo las importaciones europeas por las chinas, como informaron los tesoreros Andrés Cauchela y Salvador de Aldave, así como el factor y veedor Luis de Vivanco, en $1580^{1}$. El segundo elemento decisivo fue la existencia de una abundante mano de obra indígena (Phelan, 1959; Cummins y Cushner, 1974; Scott, 1995; Sánchez, 2004; Alonso, 2005), versada tanto en las técnicas de construcción naval como en las tradiciones náuticas elogiadas por los primeros cronistas de la exploración del Pacífico. La enorme importancia de este factor para el establecimiento de una industria considerada de interés estratégico por las autoridades españolas, quedó reflejada en la normativa laboral establecida por las primeras ordenanzas de gobierno promulgadas por Francisco de Sande en 14 de mayo de 1576. Esta legislación establecía el pago de «dos mays de oro» por cada quince días a los trabajadores indígenas empleados en el corte y arrastre de maderas para la construcción naval, o en servicio de astillero, además de una ración diaria de dieta, aunado a la condición de no emplear a los mismos individuos por más de una quincena (Valdez-Bubnov, 2017: 39). Estas cláusulas, sin embargo, no fueron respetadas, constituyendo, desde el establecimiento mismo de los astilleros filipinos, una letra muerta que, empero, sería repetida con variantes por reglamentos posteriores (Valdez-Bubnov, 2019a).

Las ordenanzas de Sande sistematizaron también la obtención de manufacturas de construcción naval como parte del tributo impuesto a las poblaciones indígenas, tales como carros, tablazón, clavazón, fibras de calafatería, estopa, y brea. El

1. Sevilla, Archivo General de Indias. En adelante, AGI. FILIPINAS, 29, N. 33. 
cobro de tributo en insumos náuticos es difícil de distinguir de otra práctica fiscal empleada por las autoridades españolas a partir de este período inicial, conocida como vandala. Esta consistía en la compra forzosa de diversas manufacturas esenciales por debajo de los precios de mercado, tales como fibra y aceite de coco para calafatería, jarcia de las palmas conocidas como abacá y gemú, así como velamen de algodón tejido. La compensación pecuniaria debida a los indígenas por concepto de vandala, sin embargo, solía retrasarse, o no llegar nunca, constituyendo una creciente deuda pública, registrada o no, por parte de la tesorería de Manila, la cual se hallaba presente desde el nacimiento mismo de la construcción naval en Filipinas. En suma, es posible concluir, en concordancia con la historiografía filipinista reciente, que la industria de construcción naval española en Filipinas tuvo su origen en procedimientos claramente deficitarios, tanto desde la perspectiva laboral, como de la obtención de insumos fundamentales (Alonso, 2001 y 2003; San Ignacio, 2001; Hidalgo, 2001 y 2009; Sánchez, 2010).

\section{LA CONSOLIDACIÓN POLÍTICO-ADMINISTRATIVA DEL ASENTAMIENTO ESPAÑOL EN FILIPINAS Y SU VÍNCULO CON LA CONSTRUCCIÓN NAVAL}

La normativa dedicada a la organización del trabajo indígena en cortes madereros y en la fábrica de navíos, así como a la obtención de manufacturas de importación y producción local, fue generada como parte de la construcción gradual del sistema administrativo de las islas, a partir de la transferencia inicial de su centro de gravedad desde Cebú a Luzón. La fundación del Cabildo Secular de Manila, en $1571^{2}$, dio paso a la institución progresiva de las Alcaldías Mayores en las provincias de Bay, Pampanga, Pangasinán, Cagayán, Ilocos, Camarines, Tondo, Tabayas, Otón (Isla de Panay), Panay, Negros, Cebú, Leyte y Samar, Ybabao, Caraga (en Mindanao), Mindoro, Calamianes, Mariveles, Balayán y Bombón, Calilaya, Butuan, y Catanduanes (Díaz Trechuelo, 2001; Hidalgo, 2009: 35). La Alcaldía Mayor representó una figura clave de la administración provincial civil, conferida a un colono español bajo sueldo, quien recibía atribuciones de naturaleza ejecutiva y fiscal sobre las «reducciones a poblado», es decir, sobre la concentración de los núcleos tribales en que tradicionalmente se hallaba organizada la sociedad indígena, denominados barangays. Estos eran reunidos en uno o varios "pueblos de indios», bajo la tutela patriarcal de un cacique, conocido, a su vez, como datu, o cabeza de barangay. Determinados conjuntos de estas unidades poblacionales fueron, a su vez, sujetos a la autoridad de un cacique principal escogido entre los cabezas de barangay, denominado «gobernadorcillo», bajo autoridad directa del alcalde mayor de cada

2. AGI, FILIPINAS, 27, N. 4. 
IVÁN VALDEZ-BUBNOV

LA CONSTRUCCIÓN NAVAL ESPAÑOLA EN EL PACÍFICO SUR: EXPLOTACIÓN LABORAL, RECURSOS MADEREROS Y TRANSFERENCIA INDUSTRIAL ENTRE NUEVA ESPAÑA...

provincia (Hidalgo, 2001: 39, 86). Por otra parte, en las regiones fronterizas, sujetas todavía a la posibilidad de enfrentamiento armado, se instituyó la antigua figura administrativa denominada Corregimiento (Sánchez, 2010: 481).

Las Alcaldías Mayores y los Corregimientos pueden ser considerados como la superestructura jurídica que operaba sobre un nivel aún más fundamental de la ocupación de las islas: la institución de la encomienda, desarrollada inicialmente en América para vincular el cobro de tributo y la movilización del trabajo forzado indígena a la presencia de colonos españoles. Las primeras encomiendas fueron concedidas por Legazpi en 1571, en Cebú, Panay, Mindanao, Negros, Leyte, Luzón, Cojos o Ymaraz, Vili, Capul, Masbate, Fuegos, Matán, Camotes, Cuyo, Fuegos y Camiguinin, Tablas y Zubugán, Bohol y Bantayán, Doblón, Banton y Marinduque, e islas de Cagayanes, y fueron registradas para la corona en $1576^{3}$. Esta potestad fue otorgada a colonos con obligación de residencia, frecuentemente incumplida, en los pueblos de sus encomendados, a cambio de responsabilidades de naturaleza militar, religiosa o meramente pública, entre ellas, la organización de la boga en buques de remo, el corte y arrastre de maderas de construcción naval, o la fábrica de navíos. El primer recuento formal de encomiendas por provincias y pueblos fue realizado en $1591^{4}$. En 1595 se listó un total de 167 encomiendas, de las cuales 32 pertenecían a la corona 5 .

La dimensión laboral de la encomienda, conocida en Filipinas, como polo o servicio, fue sistemáticamente utilizada como alternativa a la esclavitud formal, prohibida por la corona en 1574, aunque la diferencia era tenue. La primera variante náutica del polo era denominada esquipazón, o esquipazones, y consistía en la boga forzosa en galeras y otros buques de remo. Desde su institución, comenzó a ser considerada como una sentencia de muerte para los conscriptos (Hidalgo, 2009: 232). La segunda variante de la movilización de fuerza de trabajo para fines náuticos estaba dedicada a los cortes y arrastres de madera para la construcción naval, o al trabajo de astillero, y llevaba el nombre específico de ela. Cabe señalar que las elas podían ser evitadas por los nativos enviando en su lugar a un esclavo temporal, sujeto por endeudamiento, o permanente, sujeto como cautivo de guerra (Hidalgo, 2001: 86). En ambos casos, el trabajador debía pagar una cuota de sustitución, denominada opa, cuyo monto podía variar entre seis y diez pesos, y era colectada por los cabezas de barangay. Estos, a su vez, cobraban una cuota al trabajador opado a cambio de llevar a cabo el procedimiento. Las opas debían ser posteriormente libradas, en teoría, a las instancias superiores de la administración provincial, las alcaldías mayores, por parte de los encomenderos (Phelan, 1959: 99).

3. AGI, PATRONATO, 24, R. 19.

4. AGI, PATRONATO, 25, R. 38.

5. AGI, FILIPINAS, 29, N. 57. 
Es de una importancia crucial comprender que, tanto administración civil de las provincias como su vinculación con las reducciones a poblado, co-existieron con una estructura de poder paralela, constituida por el complejo entramado de las diócesis, asignadas al clero secular, y las provincias religiosas, asignadas al clero regular. En ambos casos, su establecimiento tuvo lugar durante la primera colonización de las islas. La diócesis de Filipinas fue establecida por el papa Gregorio XIII en escisión de la diócesis de México, en 1578, como una contraparte a la creación de la diócesis portuguesa de Macao (Ollé, 2013: 45). El primer religioso en ocupar el obispado de las islas fue fray Domingo de Salazar, dominico nombrado para el cargo en 1579, quien tenía una larga trayectoria en las misiones del septentrión novohispano. Salazar hizo suya la defensa de los indígenas novohispanos, liderada entonces por fray Bartolomé de las Casas, oponiéndose a la predicación de la Bula de la Santa Cruzada, promulgada por Pio V y ampliada a todos los territorios de ultramar por Gregorio XIII, en 1573 (Ollé, 2013; García-Garrido, 2016).

La creación de la diócesis y el obispado de Domingo de Salazar precedieron a la definición administrativa de las provincias religiosas asignadas al clero regular, como contraparte a la preeminencia de los agustinos, llegados con Legazpi y establecidos en la provincia del Santísimo Nombre de Jesús, en Luzón y parte de las Visayas. A partir de 1578, los agustinos debieron compartir la administración religiosa de esa isla con la orden franciscana, la cual estableció la Provincia de San Gregorio en la bahía de Manila, Camarines, y Laguna de Bay. Los dominicos, por su parte, establecieron la denominada Provincia del Santísimo Rosario en las zonas de Cagayán, Batán y Pangasinán, en la parte norte de Luzón, mientras que los jesuitas ocuparon Cebú, Bohol, Negros, Panay, Leyte y Samar, en las Visayas. La última orden en establecerse fue la de los Recoletos de San Agustín, quienes fundaron la provincia de San Nicolás de Tolentino en las islas de Zambales, Batán, Pangasinán, Palawan y Mindanao. Por otra parte, la diócesis fue elevada al rango de arzobispado, al crearse los obispados de Cebú, Cagayán y Camarines, a partir de 1595 (Phelan, 1959: 31-32; Elizalde, 2015: 192).

En suma, la triple estructura de la administración provincial, constituida por las alcaldías mayores, los corregimientos y las encomiendas, así como su vinculación directa con las provincias religiosas y con los barangays reunidos en los pueblos de indios, representan la superestructura administrativa, ideológica y social que hizo posible la movilización de mano de obra para la explotación sistemática de los recursos madereros de las islas por la industria de construcción naval española. En conjunto, la evolución político-administrativa, tanto civil como religiosa, del asentamiento español, así como la progresiva toma de conciencia de la importancia de los recursos madereros, materiales y humanos de Filipinas, es el contexto necesario para comprender la transferencia de la industria de construcción naval desde las costas de América occidental a ese archipiélago. En efecto: los primeros astilleros 
funcionales de Filipinas, situados en Cavite, bahía de Manila (Luzón), y Otón, Iloilo (Visayas occidentales), botaron al agua en, 1579 y 1580, los dos primeros navíos de altura propiamente filipinos: el Santísima Trinidad y el Santa María de Jesús (Valdez-Bubnov, 2019a: 39). En ese último año, el gobernador Gonzalo Ronquillo de Peñalosa informó al Consejo de Indias acerca de los notablemente bajos costos de producción de estos dos navíos ${ }^{6}$.

\section{LA EMPRESA DE CHINA COMO ESTÍMULO PARA LA CONSOLIDACIÓN DE LA INDUSTRIA DE CONSTRUCCIÓN NAVAL ESPAÑOLA EN ASIA}

Durante este mismo período, la primacía de los portugueses en las Molucas e India, así como la dificultad de hacer rentable el tráfico de especias hacia Europa, tuvieron por efecto el surgimiento de una corriente de opinión que consideraba necesario continuar la expansión hacia lejano oriente, específicamente, hacia China. Ya desde 1569, el fraile agustino Martín de Rada había expresado de manera explícita a Felipe II que el propósito del establecimiento en Filipinas era hacer posible una empresa de mayor envergadura, la conquista de China (Boxer, 1969; Ollé, 2002; Cervera, 2016; García-Abasolo, 2017). La carta que testimonia este suceso ha sido reproducida varias veces en la historiografía, y aquí simplemente señalaremos que, además de ese contenido, enfatiza también la importancia de la fábrica de buques en Filipinas, particularmente galeras, para servir en un posible desembarco ${ }^{7}$.

La idea de la empresa de China actuó como un fuerte estímulo para la consolidación de la industria de construcción naval española en Asia. La embajada religiosa, diplomática y militar conducida por el padre Rada a la provincia china de Hokian, en 1575, y promovida por diversos sectores hispanos durante más de una década (Ollé, 2002: 77; Chin, 2019), produjo detallados testimonios sobre los recursos demográficos, económicos y naturales de ese reino, y atrajo la atención de diversos observadores posteriores al respecto de la presencia de recursos náuticos e insumos de construcción naval en otras regiones del sureste de Asia. Dentro de la descripción de Rada de las fuerzas armadas de China, las navales ocupan un espacio privilegiado, reflejando una profunda impresión en el observador: «y toda la gente de serviçio... y aun todos los marineros que andan en armadas y navios Reales y assi como quentan todos estos entre la gente de guerra y guarniçiones creçe el numero en suma yncreyble...». Y también: «tantos navios a la vela y con zinglones que ponian espanto porque no se podian contar segun estava todo lleno dellos...». La opinión de Rada al respecto de la sofisticación técnica de los navíos chinos, empero,

6. AGI, FILIPINAS, 29, N. 33

7. AGI, PATRONATO, 24, R. 9. 

RECURSOS MADEREROS Y TRANSFERENCIA INDUSTRIAL ENTRE NUEVA ESPAÑA...

era menos favorable: «...los navios son algo torpes y de mala hechura aunque seban mucho al viento y son buenos de bolina.» ${ }^{8}$.

Otro de los participantes en esta embajada, el soldado Miguel de Luarca, se expresó en términos semejantes de los recursos marítimos y navales de China. Ante la oferta por parte del emperador Chin-Tsung de enviar una fuerza naval a Filipinas para evitar nuevas correrías piráticas por parte de sus súbditos, Luarca expresó una singular impresión ante su capacidad de movilización de buques de guerra: «ofreciéndonos 500 navíos... o 200 ... o los que quisiésemos...»». También ofreció detalles específicos sobre la hechura de los buques, en el siguiente tenor:

Por la costa tienen gran cantidad de navíos de guarnición con sus generales y capitanes, que en la sola provincia de Oquian dizen que hay 400, de los quales nosotros vimos gran parte, los navíos algunos son grandes, pero muy flacos, que de la lumbre del agua arriba todo es obras muertas de una tabla delgada, y no tienen ligazón?

Por otra parte, el testimonio más temprano al respecto de la posibilidad de explotar los recursos náuticos de China se encuentra en el Discurso de la navegación que los Portugueses hazen à los Reinos y Provincias del Oriente, y de la noticia que se tiene de las grandezas del Reino de la China, publicado por el militar, diplomático y literato español, Bernardino de Escalante, en $1577^{10}$. Este autor señaló que las cosas del mar tenían tanta estimación en China que:

abita poco menos gente en el agua que en tierra. Ayudales mucho à esto la abundancia que tienen de madera, y mineros de hierro, y otras cosas necessarias para la arte del navegar, con que les es facil, hazerlos à muy poca costa. A los mayores navios que tienen, los nombran Iuncos, y hazen los para guerra muy grandes, con castillos muy altos en popa y proa, como las naves Levantiscas... Desta mesma hechura y grandeza tienen otros para carga, pero son mas baxos de popa y proa. Otros navios ay menores, que llaman Bancoens, que traen tres grandes remos por vanda, que los bogan quatro y seis hombres à cada uno dellos, y sirven les mucho, para entrar y salir las barras, y otros que llaman Lanteas, que bogan siete y ocho. Destas dos suertes de navios aunque son para carga, se sirven los cossarios y ladrones, que ay hartos por todas aquellas costas, è Islas por ser mas ligeros. Tambien usan de unos navios largos como galeras, aunque sin palamenta, ni espolon, en que cargan infinidad de mercaderias, para baxarlas y subirlas por los rios adentro que llevan poca agua, à la manera de las chatas de Flandes. Ay de otras suertes de navios y barcos diferentes

8. Rada, M. de. Relaçion Verdadera de las cosas del Reyno de TAIBIN (1575). Bibliothèque Nationale de Paris: Fonds Espagnol, 325.9 (MF 13184), f. 15-30. Transcripción de Dolors Folch Fornesa y Alexandra Prats. https://www.upf.edu/asia/projectes/che/s16/radapar.htm

9. Biblioteca Nacional de Madrid, MSS/2902, fols. 80-81.

10. El libro recibió licencia en 1567, y fue publicado en 1577. 
tanta muchedumbre, que ponde admiracion el proprio Reino: porque les es vedado que nadie salga del, para parte ninguna: aunque antiguamente navegaron mucho, conquistando Islas y Reinos de aquel mar, hasta llegar à la India de que ay oy dia memoria suya en la costa de Coromandel... (Escalante, 1577: fol. 55).

Finalmente, Escalante incluyó una reflexión de importancia crucial para la historia de la construcción naval española en el Pacífico: la combinación de diseños, técnicas y materiales propios de la región, con las prácticas de la industria europea, en este caso, específicamente la portuguesa:

Traen en todos estos navios corredores muy curiosos en popa sobre el governalle, de que à su imitacion usan aora los Portugueses en sus galeones y naos de la India, $\mathrm{y}$ de un betumen que aprendieron dellos, à que llaman La pez, que se haze de cal y azeyte de pecado, y del uname viejo muy picado que le ponen entre el costado de las naos, y otro aforro nuevo de tabla, que se les echa encima, hasta do llega de ordinario el agua, quando van cargadas, despues en lugar de brea tornan à cubrir el aforro nuevo con el mesmo betumen, que es tan provechoso al tablado, que no entre jamas gusano en el, y haze se en poco tiempo con el agua, tan duro como piedra; y con esto les duran a los Chinas mucho tiempo sus navios: de suerte que ay algunos Iuncos que les han puesto quatro y cinco vezes la pez, con que el costado dellos parece un muro: pero quedan con esta fortaleza muy pesados para andar à la vela (Escalante, 1577: fol. 58).

Los testimonios de Rada y Escalante sirvieron de fundamento para otra obra que describió los recursos náuticos de aquel reino de oriente. Se trata de la Historia del Gran Reino de la China, publicada por el fraile agustino Juan González de Mendoza en 1585 (Sola, 2016: 12). Pese a la presencia en el texto de transcripciones casi literales de algunos pasajes provenientes de los dos autores ya mencionados, el libro de González de Mendoza posee un interés particular. En efecto, algunos detalles técnicos sobre la industria de la construcción naval china son más específicos, lo cual se explica por el hecho de que tuvo a su alcance, según su propio testimonio, no solo los manuscritos de Rada, sino también una serie de obras que aquel fraile trajo consigo al retornar de su embajada, las cuales, desafortunadamente, no aparecen identificadas. Esos libros, según el autor, fueron leídos e interpretados en Filipinas, y eran «para hazer navíos de muchas maneras» y saber «como se ha de navegar: con las alturas de los puertos, y la calidad de cada uno en particular». Otros trataban «de la architectura, y... todas las maneras de fabricar, con el ancho y largo que el edificio ha de llevar para que tenga proporción», y también los había «para hacer armas e instrumentos de guerra: y para saber formar esquadrones» (González, 1585: 90-92). El capítulo XXI, dedicado a la construcción naval, lleva por título «De la manera de los navíos, así por la mar, como por los ríos, que son muchos, y muy grandes...», e incluye, además de las descripciones de tipos de buques derivadas de Rada y Escalante, el importante detalle de los materiales de calafatería empleados 
IVÁN VALDEZ-BUBNOV

LA CONSTRUCCIÓN NAVAL ESPAÑOLA EN EL PACÍFICO SUR: EXPLOTACIÓN LABORAL, RECURSOS MADEREROS Y TRANSFERENCIA INDUSTRIAL ENTRE NUEVA ESPAÑA...

en la construcción naval china, así como el peculiar diseño de bombas de achique aparentemente propulsadas por pedales:

El betum con que los brean (que como dixe se halla en todo el Reyno en mucha abundancia) se llama en su lengua Iapez, y lo hazen de cal, y azeyte de pescado, y una pasta, llamada Uname, que demas de ser fuerte... cria muy poca broma, que es causa que dure un navio doblado tiempo que uno de los nuestros, aunque les quita mucho de la ligereza. Las bombas que traen en estos navios son differentissimas de las q nosotros usamos, y de mas ingenio y probecho, porque son hechas de muchas piezas a la manera de Anorias que las ponen al largo de los costados de les navios por la parte de dentro, y desagotan tan facilmete que un hõbre solo sentado con solo menear cõ los pies una rueda, como quien sube por unas gradas, dexa en un quarto de hora sin agua un gran navio por mucha que aya hecho (González, 1585: 103).

De igual interés para el estudio de la construcción naval en el Pacifico es el siguiente detalle al respecto de la construcción de los juncos de guerra, y sus coincidencias con la fábrica portuguesa: «quando se hazen de intento para cosa de guerra, los hazen con castillos altos en popa y proa, al modo de los que traen las naos de Levante, y las de los portugueses que van a la India» (González, 1585: 102).

Desde el punto de vista de la historia de la industria de la construcción naval española en Asia, la obra de González de Mendonza contiene, además, otra clave de importancia crucial: su incorporación, en el libro tercero, de las observaciones registradas por el fraile franciscano Martín Ignacio de Loyola, compiladas en forma manuscrita entre 1582 y 1585, bajo el título Itinerario alrededor del mundo (Tellechea, 1989). Estas presentan la descripción de los «reynos comarcanos» a China: Aynao, Manar, la provincia de Tunkín, y el reino de Champa, todos ellos provistos de «maderas galanísimas... y grandes mantenimientos», mientras que el reino de «Camboja» (Camboya) en Cochinchina, aparece descrito como «...de gente muy aficionada a la mar, con infinidad de baxeles...». En este sentido, también destaca el reino de «Syan» (Siam), «a trezientas leguas de Macao, a donde van los portugueses a contratar...», el cual era «muy rico en metales, y maderas olorosas y galanas» (González, 1585: 346-366). Esta es probablemente la primera mención específica de Camboya y Siam como regiones pródigas en insumos náuticos, potencialmente útiles para la construcción naval hispana. La presencia de mercaderes de ambas naciones en Manila, sin embargo, se remonta a los primeros tiempos de la ocupación española, y fue registrada por Antonio de Morga en sus Sucesos de las Islas Filipinas (publicada en 1609), en la siguiente forma:

...de Sian y Camboja, vienen raras veces algunos navíos a Manila, que traen algún menjuy, pimienta, marfil y mantas de algodón, rubíes y zafiros mal labrados, y angazados, algunos esclavos, cuernos de badas, pellejos, uñas y muelas deste animal, 
y otras bujerías; y en retorno, llevan las que ay en Manila; su venida y buelta es, entre Brisas y Vendabales, por los meses de abril, mayo y junio... (Morga, 1890: 315).

Por otra parte, la obra de fray Gabriel de San Antonio, impresa en 1604, contiene la siguiente apreciación de los recursos siameses:

Tiene este reyno muy ricos edificios y muchos Ríos, buenos puertos, lindas barras, y usan de galeras con remos. En toda esta tierra se halla la madera preciosa y calamba aguila.... La Ribera del río es fresquísima, y muy poblada de diferentes árboles, y de casas de recreación. El río cerca toda la ciudad, y la ciudad tiene una cerca de ladrillo de cié brazas de alto y tres de ancho, y muchas almenas. Dentro tiene cien lagunas, y en la una pueden surgir muchos navíos, aunque sea de quinientas toneladas... (San Antonio, 1604: 23,36).

En suma, a partir de la embajada del padre Rada, se hicieron patentes tanto la riqueza de la cultura marítima como los recursos de construcción naval de China, y de otras naciones del sureste asiático, especialmente Camboya y Siam, en un contexto en que la ocupación de Filipinas era considerada como una posible etapa transitoria hacia nuevas y mayores conquistas.

\section{EL PADRE ALONSO SÁNCHEZ Y LA EVALUACIÓN DE LA CONSTRUCCIÓN NAVAL EN NUEVA Y ESPAÑA Y FILIPINAS}

Durante los primeros años del asentamiento español en Filipinas, los astilleros americanos continuaron produciendo navíos para la naciente carrera del Pacífico. En 1577, Diego García de Palacio, entonces fiscal de la Audiencia de Guatemala, inició la construcción de dos galeones en el astillero de Realejo, el Santa Ana (400 toneladas), y el San Martín (500 toneladas). Esto fue parte de su campaña política para obtener, no solo la gubernatura de Filipinas, sino también el monopolio sobre la ruta transpacífica desde una nueva base en América central (Arróniz, 1980). La historiografía reciente ha señalado que, además de estos propósitos, García de Palacio fue también uno de los más activos promotores de la idea de usar las Filipinas como una base para la conquista militar de China (Cervera, 2013). La construcción del Santa Ana y el San Martín fue simultánea a la gestación de estas ideas, y coincide también con la tratadística militar y naval por la que este personaje es mejor conocido. El proceso que condujo a la botadura de ambos galeones, sin embargo, fue largo y oneroso para la Real Hacienda, con una duración de varios años y un costo total de 46.000 pesos. Posteriormente, uno de esos buques fue vendido, siendo propiedad de la corona, a Lope García de Palacio, hermano del constructor y suplicante, por tan solo 16.000 pesos (Arróniz, 1980: 127).

Es posible que el juicio de corrupción contra las empresas de los García de Palacio, iniciado a partir de este punto, haya incidido en la decisión formal de 

RECURSOS MADEREROS Y TRANSFERENCIA INDUSTRIAL ENTRE NUEVA ESPAÑA...

transferir definitivamente la industria de construcción naval de la carrera del Pacífico desde Nueva España a Filipinas, pero otros factores también deben ser tomados en cuenta. Existe un documento que precisa los motivos económicos que hacían deseable esa transferencia, escrito por uno de los principales promotores ideológicos de la empresa de China, el fraile jesuita Alonso Sánchez. Aunque no tiene fecha, su redacción indica que fue escrito en Nueva España, pues, al referirse a las opiniones acerca del potencial de Filipinas como centro de la construcción naval del Pacífico, el padre Sánchez empleó varias veces el giro «me dicen de allá...» ${ }^{11}$. Es preciso considerar que, en 1580, con la unión de las coronas de España y Portugal en la persona de Felipe II, el autor fue comisionado como embajador al enclave portugués de Macao, misión que resultó ser extremadamente azarosa, y que llevó a cabo entre los años de 1582 y 1583 (Cervera, 2013: 225-226). Por ende, es altamente probable que el manuscrito en cuestión haya sido producido entre 1580 y 1581 , antes de que el padre Sánchez emprendiese ese proyecto, y cuando los dos galeones de García de Palacio se hallaban todavía en grada, o a punto de ser botados.

Según Manuel Ollé, por otra parte, el buque en el cual el padre Sánchez zarpó rumbo a Filipinas, en marzo de 1581, llevaba por nombre San Martín, y estaba bajo el mando de Luís de Sahagosa. Esto abre la posibilidad de que se tratase, precisamente, de uno de los dos galeones construidos por García de Palacio. Más aún, este mismo autor señala que fue precisamente en ese buque que embarcó rumbo a Filipinas el recientemente nombrado obispo, fray Domingo de Salazar, a quien ya hemos mencionado en el contexto de la administración religiosa de Filipinas. Según Ollé, ambos personajes, el padre Sánchez y el obispo Salazar, se conocieron en el viaje, y ciertamente debieron tener ocasión de intercambiar puntos de vista al respecto de la conquista militar de China, y las particularidades de la construcción de navíos en Filipinas (Ollé, 2013: 45).

Por ende, el dictamen del padre Alonso Sánchéz, que analizaremos a continuación, debe haber sido escrito en Nueva España, antes de que el autor se embarcara en el mencionado viaje, o tal vez durante la travesía. Su contenido representa un detallado alegato al respecto de las inconveniencias de mantener la industria de construcción naval en el Realejo, «...o en cualquier otro puerto del Pirú o Nueva España...», debido a su "grande trabajo, y excesiva costa». El jesuita precisaba que, con los gastos de construcción de un solo galeón americano, podrían fabricarse cuatro filipinos. Según su cálculo, el costo de los primeros podía alcanzar los 60.000 pesos, mientras que los costos de los segundos, hechos en Filipinas, podían oscilar entre 6 y 8.000 pesos, de 500, 600 y más toneladas de porte.

Para explicar esta enorme diferencia, el padre Sánchez citaba tres causas principales. La primera era la abundancia de maderas de alta calidad en Filipinas, de

11. AGI, PATRONATO, 260, N. 2, R. 46. 
la cual «hay muchisima en las islas, de muchas suertes, fuertes y blandas, para la armadura y tablazon, como para curbas y ajustes». La segunda razón era el bajo costo del hierro importado de China, que podía obtenerse en Manila a 10 reales el quintal. La tercera era la ya conocida destreza de los indígenas para la carpintería y la manufactura de herrajes. También señalaba la abundancia de plomo, aunque sin señalar su procedencia, y que «hay alla mucha brea y aceite de cocos, y lo demás necesario para calafatear y para todo...». Finalmente, explicaba claramente que era preciso hacer venir desde España oficiales experimentados para guiar a los indígenas en «dar el galibo a los navíos, y lo mismo para las herrerías...». Consideraba también que «tienen mucha destreza y facilidad para todo y aún dellos mismos se irán haziendo oficiales...» ${ }^{12}$.

Sin embargo, la mayor preocupación del padre Sánchez era la provisión de jarcia, la cual, claramente consideraba insuficiente, o problemática, no solo en el caso de Filipinas, sino de toda la Mar del Sur. En primera instancia, señalaba que la práctica inicial de hacerla llegar a Filipinas desde España, a través del eje VeracruzAcapulco, era «de excesivo trabajo y costa», por lo cual sugería que se promoviera allí el cultivo de una yerba americana denominada zacate, «a manera de carrizo... y semejante al cáñamo», proponiendo llevar las semilla allá y aprovechar la tierra usada para cultivos de arroz, la cual consideraba «muy buena y apropiada» para tal uso. Este cultivo debía promoverse entre los indígenas de Filipinas a través de los encomenderos, otorgando «ayuda y favores» a los que lo quisieran hacer, haciéndoles «libres qualquier otra ocupacion y trabajo de guerra, ni de paz...». Para el trenzado de la jarcia, en cambio, proponía la importación a Filipinas de esclavos comprados en India, quienes, además de ocuparse en este arte, podían enseñar también a los indígenas. En conjunto, este cultivo ofrecía grandes ventajas de economía en relación con desarrollar la misma industria en Nueva España, pues los esclavos se podían comprar en India por 30 y 40 pesos, mientras que en México se tasaban entre 300 y 400 pesos, «y con ello se ahorra mucho de lo que... se gasta en ordinarios jornales» de los indígenas asalariados. A esto añadía, que los esclavos podrían, además, utilizarse en toda clase de obras públicas, «y jornadas y provisiones de los almacenes y navíos...». Más aún, esperaba que la descendencia de los esclavos permitiera formar poblaciones de calafates, herreros, y otros oficios náuticos, en contraste con los costos de 400 y 500 pesos al año que representaban los salarios de estos especialistas empleados en los astilleros filipinos ${ }^{13}$.

Como alternativa a estas dos opciones, el padre Sánchez sugería también la posibilidad de aprovechar para este propósito otras plantas locales, específicamente el anabo («que es como el cáñamo»); el bejuco (« que es como mimbre muy correoso

12. Ibidem.

13. Ibidem. 

RECURSOS MADEREROS Y TRANSFERENCIA INDUSTRIAL ENTRE NUEVA ESPAÑA...

y suelto»); y la fibra de coco (« que es como cerdas»), la cual, como hemos ya señalado, se empleaba también como fibra de calafatería. En caso de que estos recursos locales no fuesen suficientes, o suficientemente apropiados, el padre Sánchez sugería la solución radical de comprar jarcia ya manufacturada en la India, así como anclas, y otros materiales: salitre, para la fabricación de pólvora, estaño, esclavos, y toda clase de provisiones. Para ello, consideraba necesario establecer una vía marítima regular entre Manila y Malaca, con fragatas de portugueses y castellanos. Al respecto de este comercio de esclavos e insumos náuticos con la India portuguesa, el padre Sánchez iba más lejos, señalando que, debido a la unión de coronas, este tráfico sería benéfico para ambas partes, "por las muchas cosas que se pueden comunicar», y por «respeto de la union necesaria entre castellanos y portugueses, y por otras cosas más graves, y de importancia». ${ }^{14}$

El dictamen del padre Sánchez es importante porque contiene también uno de los más tempranos testimonios acerca de los efectos sociales de la construcción naval española en Filipinas, así como uno de los primeros indicios de un profundo conflicto entre la iglesia y el Estado en torno a la legislación laboral, y su incumplimiento o ineficacia. En efecto, el dictamen suplicaba «que se mire y pondere mucho las causas por que los navíos allá salen tan baratos», las cuales no eran otra cosa que la explotación de las poblaciones indígenas:

es porque a los indios se les paga tan poco que todos juzgamos que se les haze muy notorio agravio porque no se les da sino a quatro reales cada mes sin comida ni vestido y mal y tarde pagados. Yo descanso mi conciencia, y cargo la de Su Magestad y de sus Ministros, con avisar que si se toma de proposito el mandar que (en Filipinas) se hagan los navíos, se tome tambien el mandar que se les pague lo justo y razonable y que se vaya dando como fueren trabajando porque en esto todos lo que gobiernan hacen gravísimos y lastimosos agravios a los naturales sacándolos de sus casas y sementeras y haciéndoles que vayan a cortar madera y arrastrarla y traerla al astillero, y labrarla, y muchas veces sin darles ninguna ayuda para comida ni instrumentos... (dejando) a la mujer e hijos, y su casa de la cual se ausentan por mucho días y aún meses en estas obras, en lo qual se le siguen a Su Magestad muy mayores daños en que se muera la gente, y se despueblen las tierras y muchos se alteren y levanten, como lo hacen, y salirle un navío a Su magestad en mil pesos mas o menos supuesto que es justo es de poca consideración, y a los indios les es su vida, y remedios, y sosiego ${ }^{15}$.

Salta a la vista, además de la cruenta explotación de los indígenas descrita por Sánchez, la diferencia entre el pago de «dos mays de oro» por cada quince días de

14. Ibidem.

15. Ibidem. 
trabajo en la construcción naval o en los cortes madereros, estipulado por las ya mencionadas ordenanzas del gobernador Francisco de Sande en 1576, y el jornal de 4 reales al mes registrado por este testimonio. Es probable que este cambio haya sido impuesto con el ascenso del ya mencionado Gonzalo Ronquillo al gobierno de las islas, en 1580. Se trataba de una tasación que, según el padre Sánchez, «el gobernador allá hizo a su gusto...» y que, como indican fuentes documentales posteriores, no era suficiente para «mantener juntos el alma y el cuerpo» de los trabajadores de la construcción naval. Por ende, el padre Sánchez sugería que se mandara que «se juntasen el gobernador, oficiales y algunos encomenderos, y el obispo, y algunos religiosos, y miradas bien y christianamente las cosas» se tasara el jornal para estas, y otras obras públicas. Finalmente, sugería también que se ordenara llevar registros puntuales del uso de los situados en operaciones de construcción naval, el cual, según el autor, distaba mucho de ser transparente: «enviar acá a Su Magestad la quenta de todo, muy por menudeo y de como se gastó en aquello...» ${ }^{16}$.

A partir de los contenidos de este manuscrito, es posible sugerir que las recomendaciones del padre Sánchez definieron la política de administración laboral y cortes madereros para la construcción de navíos en Filipinas. Esta idea aparece reforzada por el hecho de que compartió la travesía con el recién nombrado obispo, Domingo de Salazar, muy probablemente a bordo de uno de los galeones construidos en Realejo por Diego García de Palacio. Apenas iniciada la residencia del obispo Salazar en Manila, este llevó a cabo una política orientada a reducir las atribuciones de los agustinos, entonces la orden más extendida en las islas, acusándola de excesos y abusos en contra de la población. Esta política fue apoyada por el cabildo secular de Manila, el cual tenía instrucciones precisas de colaborar estrechamente con el primer obispo, expedidas por Felipe II en 1579, probablemente en previsión de las tensiones que surgirían ante las amplias facultades otorgadas simultáneamente al gobernador Ronquillo. Las primeras misivas de Salazar denunciado los efectos sociales de la construcción naval datan precisamente de este período (Ollé: 2013 p. 45, 46). Significativamente, estas incluían el mismo punto del pago de cuatro reales a los trabajadores de la construcción naval y las esquipazones, en términos muy semejantes a los utilizados por el padre Sánchez en su dictamen:

...la paga que les dan es muy poca; que solamente dan á cada uno por un mes quatro reales; y esto tan mal pagado, que los más se quedan sin ello y los pueblos de donde los sacan reparten entre sí la paga ó la dan á los que sacan para el remo; y esto es cosa muy çierta y averigüada [...] Lo mesmo pasa al cortar de la madera. Que haçen trabaxar á los yndios en cosas del servicio de Vuestra Magestad y les pagan poco, mal y tarde, y muchas veçes se quedan sin la paga ${ }^{17}$.

16. Ibidem.

17. AGI, FILIPINAS, 6, r. 10, n. 180. 

RECURSOS MADEREROS Y TRANSFERENCIA INDUSTRIAL ENTRE NUEVA ESPAÑA...

En Octubre de 1581, el obispo Salazar convocó a una junta para discutir el incumplimiento de la Real Cédula de prohibición de la esclavitud de 1574, señalando su omisión por parte del gobierno de Ronquillo. En una segunda junta el obispo trató el tema de la encomienda y los polos, así como el vínculo de ambos con la construcción naval. En una tercera junta, celebrada en 1583, se abordó el proyecto de expansión a China, en la que Salazar nuevamente manifestó su coincidencia con el padre Sánchez al respecto de la posibilidad de llevar a cabo la conquista militar y espiritual de ese reino. En 1586 tuvo lugar una última reunión de todos los estamentos de Manila para redactar un memorial de las sesiones, el cual debía ser entregado a la corona por el mismo padre Sánchez, y que condujo a su denominación posterior como «Sínodo de Manila» (Cummins y Cushner, 1974: 121; Ollé, 2013: 47).

De manera paralela a estas sesiones, el Consejo de Indias creó una nueva figura gubernativa para Filipinas, la Real Audiencia de Manila, cuya presidencia recayó en el nuevo gobernador y Capitán General de Filipinas (a partir de 1584), Santiago de Vera. Por medio de este nuevo órgano de gobierno, el Consejo de Indias ordenó al gobernador que promoviese la fabrica en las islas de buques de remo y de alto bordo, por cuenta de la Real Hacienda, al tiempo que confería a los oidores la responsabilidad de informar sobre el número y estado de los buques en servicio de la corona ${ }^{18}$. Con estas medidas, la formalización de la transferencia de la industria de construcción naval desde América a Filipinas quedó finalizada. La proximidad cronológica de este hecho con la interacción personal entre el padre Sánchez y el obispo Salazar es significativa, y permite fechar con precisión este importante cambio de política industrial.

En este sentido, es preciso considerar también que la ya mencionada experiencia de los astilleros de Cavite y Otón, coincidente con el escándalo de los galeones construidos en Realejo, y aunada a la decisión formal de transferir y fomentar la industria de construcción naval en Filipinas como parte de las responsabilidades de la Audiencia, anunció la apertura de otros astilleros, temporales o semi-permanentes, en distintos enclaves del archipiélago: Marinduque, a 40 leguas de la bahía de Manila; Mindoro, a 50 leguas; Camarines, también a 50; Masbate; a 70; y Bagatao, en Albay, e Ybalon, en Bagatan, ambos distantes a 80 leguas (Valdez-Bubnov, 2017: 244). Es preciso considerar que la locación de estos astilleros se encontraba directamente relacionada, no solamente con la existencia de enclaves costeros apropiados para la botadura de navíos y para el establecimiento de almacenes, sino también con la abundancia de los recursos madereros disponibles en su cercanía. Desde esta perspectiva, la función reguladora de la administración provincial, civil y religiosa, y su vínculo con la movilización de fuerza de trabajo indígena aparece en toda su importancia.

18. AGI, PATRONATO, 25, R. 2 
En 1590, la Audiencia fue disuelta por el gobernador Vera, pero esto ciertamente no obstruyó la consolidación de la industria de construcción naval, sino que mantuvo la relativa autonomía de los encomenderos para imponer cuotas de trabajo forzado. Esto, a su vez, mantuvo activa la beligerancia del obispo Salazar. En ese mismo año arribó a las islas el nuevo gobernador, Goméz Pérez Dasmariñas, con instrucciones que precisaban abordar, en coordinación con el obispo, el problema del incumplimiento de las ordenanzas, sobre todo en relación con el cobro de tributos en las encomiendas. En 1591, Salazar definió el problema a partir de la existencia de dos tipos de encomiendas, las adoctrinadas, con derecho al cobro de tributo, y las que no lo eran. Así, sin negar la institución de la encomienda, el obispo enfatizó la relación entre la fiscalidad pública y la evangelización, legitimando, de hecho, la explotación de las poblaciones indígenas (Ollé, 2013:47). Al año siguiente, Dasmariñas promulgó unas nuevas ordenanzas dedicadas a la fuerza de trabajo indígena, así como a las vejaciones cometidas contra ellos por encomenderos, alcaldes mayores, justicias y religiosos. ${ }^{19}$ Salazar, por su parte, embarcó con destino a la corte de Madrid para exponer sus posiciones a Felipe II, en particular al respecto de la anulación de la Audiencia, muriendo en Madrid en 1594. En cuanto a los debates sobre la empresa de China, estos fueron formalmente cancelados por Felipe II en 1593, prohibiendo, a un mismo tiempo, la navegación directa desde el Perú a Filipinas y China (Ollé, 2013: 47-48, 49).

A partir de estos cambios, la corona buscó impulsar el desarrollo de la industria de construcción naval en Filipinas. Desde 1592, había prohibido el reclutamiento indígena para esquipazones, quedando reservadas para la población china (Hidalgo, 2009: 233, 235). En 1607, el Consejo de Indias expidió, tal como lo había sugerido el padre Sánchez, una Real Cédula exigiendo justificar el uso de caudales de la Real Hacienda en la construcción naval, lo cual se extendía también al pago de salarios a los trabajadores indígenas (McCarthy, 1995: 166; Sales-Colin, 2011: 68). A esto se añadió la Real Cédula de 26 de mayo de 1609, relativa al cobro de tributos, a la prohibición de su permuta por servicios laborales, y a la esclavitud por deudas ${ }^{20}$. Al respecto de las esquipazones, se especificaba que las embarcaciones de remos debían construírse con cubiertas, para proteger a los remeros de los elementos, además de confirmar la prohibición de forzar los naturales a la boga, la cual debía ejercerse como trabajo asalariado, preferentemente reservado para chinos y japoneses. Esta diferenciación étnico-laboral se extendió explícitamente a los cortes de maderas, con una serie de precisiones de importancia crucial para la institucionalización de la industria. La cédula ordenaba «que no se repartan indios en más, ni menos número»

19. AGI, FILIPINAS, 18B, R. 2 , N. 19.

20. AGI, FILIPINAS, 329, II Parte de su contenido, reproducido en Cummins y Cushner, 1974: 198. 

RECURSOS MADEREROS Y TRANSFERENCIA INDUSTRIAL ENTRE NUEVA ESPAÑA...

para obras públicas, en particular, para «cortes de maderas, navegaciones de Caracoas, y otras fábricas de esta calidad, en que está interesada mi Real Hacienda». Para ello, se debía llevar «alquilados chinos, y iapones, que a la sazón se hallaren en Manila, y avrá entre ellos suficiente número... que vayan a estos ministerios, si les dan el justo jornal de su trabajo... por excusar el concurrente número de indios...». Sin embargo, también especificaba que "en caso de que no se pueda quitar el repartimiento...», ya porque los chinos y japoneses no quisieran o no pudieran cumplir con «la urgencia y necesidad de estas obras públicas», se autorizaba a utilizar los medios que se juzgaren apropiados para que los indígenas acudieran «libre y voluntariamente». Más aún, se añadía que, en caso de no haber voluntarios, se autorizaba la imposición de trabajo forzado, «permiso que se compelan algunos indios para trabajar en estas ocupaciones», bajo la condición de que «este repartimiento no se aga sino para cosas muy forzosas, y que no se puedan escusar, pues en materias tan odiosas no a de bastar el mayor beneficio de mi Real Hacienda, o más comodidad de la república; y todo lo que no fuere preciso para su conservación...» (Valdez-Bubnov, 2019: 46-47).

Las implicaciones de esta legislación son claras: la cédula de 1609 buscaba transferir los cortes madereros y la construcción naval a las poblaciones de origen chino y japonés, como trabajo asalariado. Sin embargo, el mismo texto preveía la posibilidad de que esto no fuese factible, permitiendo, en casos de urgencia o interés público, utilizar el trabajo forzado de los indígenas para los mismos propósitos. Es preciso considerar que, ante la cancelación de la empresa de China, y la consolidación de las rutas transpacíficas, la construcción naval representaba una actividad absolutamente vital para la subsistencia del establecimiento español en Filipinas, generando una demanda constante de navíos y galeras para distintas funciones. Así, el resultado de la peculiar ambivalencia de la cédula de 1609 fue permitir, al mismo tiempo que se prohibía, la forma más frecuente, opresiva e intensa del trabajo forzado indígena (Valdez-Bubnov, 2019: 47). Esta apreciación queda confirmada por la frecuencia de las rebeliones indígenas durante el período formativo de la industria de construcción naval en Filipinas: 1571, 1574, 1582, 1585, 1587, 1589, 1596, 1601, 1607, 1610, 1612, $1615,1621,1622,1627,1629,1630$ y 1631, varias de las cuales tuvieron su origen en campañas de cortes madereros y operaciones de construcción naval (Prieto, 1984: 144-145; Palanco, 2004: 2-22). La práctica de transferir las esquipazones y los trabajos de construcción naval a la comunidad china, por otra parte, tuvo efectos análogos, con serias rebeliones en 1593, 1603, 1639, 1662-63 y 1686 (Ruiz-Stovel, 2009: 47, 50; Díaz, 1890: 631). 
IVÁN VALDEZ-BUBNOV

LA CONSTRUCCIÓN NAVAL ESPAÑOLA EN EL PACÍFICO SUR: EXPLOTACIÓN LABORAL, RECURSOS MADEREROS Y TRANSFERENCIA INDUSTRIAL ENTRE NUEVA ESPAÑA...

\section{LOS INTENTOS POR TRANSFERIR LA INDUSTRIA DE CONSTRUCCIÓN NAVAL DESDE FILIPINAS A LA INDIA, CAMBOYA Y SIAM (1598-1668)}

La consolidación de la industria de construcción naval en Filipinas hizo posible una nueva etapa de la expansión hispana en el Pacífico. En 1584, el obispo de Malaca, Joao Ribeio Gaio, expresó la posibilidad de conquistar los reinos de Aceh, Patani y Siam, por medio de expediciones navales enviadas desde Malaca y Filipinas. En 1586, el gobernador de Filipinas, Santiago de Vera, intentó enviar una embajada a ese último reino, con el fin de consolidar la obtención de insumos estratégicos (Rodao, 1997: 8, 27). Por otra parte, en 1593, el gobernador Dasmariñas, recibió una embajada del rey Prauncar de Camboya, refugiado entonces en Laos, solicitando apoyo militar en contra de una invasión siamesa, llevada a cabo "con mucha gente de guerra y elefantes», contra su capital, Chordemuco (Aduarte, 1693: 189, 195: Morga, 1890: 37). Aunque el gobierno de Manila permaneció neutral, varios mercenarios portugueses y españoles se involucraron en las luchas de poder en la corte camboyana, en el contexto de tres guerras libradas contra Siam, en 1596, 1598, y 1602. Las relaciones con la corte siamesa fueron restablecidas bajo el gobierno de Francisco Tello de Guzmán (1596-1602), quien obtuvo permiso para el establecimiento de una factoría por parte del rey Naressuan de Ayutthaya, pero la creciente presencia de la Compañía Holandesa de las Indias Orientales obstruyó el desarrollo de ese comercio. Tello también buscó un acuerdo comercial con el establecimiento portugués de Macao, en China, en 1598, con el fin de obtener insumos militares, como hierro, cobre y salitre. El gobierno chino autorizó el establecimiento de una factoría de españoles en Pindal, a diez leguas de Cantón, pero la resistencia de los portugueses condujo a su abandono el año siguiente (Rodao, 1997: 28-33, 35).

Durante este período, la construcción naval en Filipinas comenzó a mostrar su inestabilidad estructural. El indicio más temprano en este sentido es la Real Cédula de 1 de mayo de 1608, expedida al gobernador Fernando de Silva a resultas de un informe enviado por el procurador general de las islas, Fernando de los Ríos Coronel. La Cédula ordenaba suprimir la figura administrativa del Patrón de Ribera, de la cual ignoramos fecha de institución. El motivo de la orden era la ineficacia de esta figura administrativa en asegurar el buen aderezamiento de los navíos, así como su construcción y mantenimiento con maderas de alta calidad. Por ello, se mandaba que las responsabilidades de este funcionario fueran absorbidas directamente por los oficiales de la Real Hacienda. Se trata de un documento importante, pues representa el primero de muchos esfuerzos por parte de la real administración por controlar la dimensión técnica de los procesos productivos de los astilleros filipinos ${ }^{21}$.

21. AGI, FILIPINAS, 340, L.3, F.44R. 

RECURSOS MADEREROS Y TRANSFERENCIA INDUSTRIAL ENTRE NUEVA ESPAÑA...

Significativamente, Ríos Coronel también estuvo involucrado en la mecanización de la fábrica de tablazones para la construcción naval en Cavite, por medio del establecimiento de una sierra de agua. Una Real Cédula de 16 de agosto de 1608, concedió al procurador la concesión exclusiva de este ingenio por un período de diez años. Significativamente, el texto de la cédula indica que Ríos Coronel obtuvo este privilegio, probablemente lucrativo, a partir de su representación de las «vejaciones y molestias que se hacían a los naturales empleados en cortar las maderas» ${ }^{22}$. Dado el protagonismo del procurador general en ambas medidas, además de su proximidad cronológica, es probabable que la eliminación de la figura del Patrón de Ribera y el establecimiento del aserradero mecánico estuvieran estrechamente relacionados.

En un sentido análogo, en 1619, el capitán de maestranza del astillero de Cavite, Sebastián de Pineda, preparó un largo memorial para el Consejo de Indias, informando de los principales tipos, calidades y usos de las maderas empleadas en la construcción naval filipina ${ }^{23}$. Dado que sus contenidos al respecto de tipos maderas en uso han sido detallados por la historiografía reciente, no los repetiremos aquí, y remitimos al lector a esos estudios (McCarthy, 1995; Crailsheim, 2014; Wing, 2015; Valdez-Bubnov, 2017 y 2019).

Además de esto, el memorial de Pineda incluye también importantes noticias sobre la dimensión laboral de los problemas del astillero, que revelan cambios al respecto de la situación registrada anteriormente por el padre Sánchez y el Obispo Salazar. El capitán de maestranza señalaba que los indígenas movilizados para cortes madereros y trabajos no calificados de construcción naval percibían de siete a ocho reales al mes, así como raciones diarias de medio celemín de arroz. Aquellos empleados en trabajos calificados percibían diez o doce reales al mes, mientras que los maestros, encargados de labrar los mástiles, vergas y masteleros, recibían tres o cuatro pesos de ocho reales al mes, y doble ración de arroz. Los indígenas que trabajaban el hierro en el astillero eran pagados doce reales al mes, en contraste con los chinos, que recibían veintiocho reales al mes, y una ración de medio celemín diaria. El informe incluye además detalles técnicos de siete galeones, seis construidos en Filipinas, y uno en la India, comprado en Pinacan, los cuales se hallaban a la sazón anclados en el puerto de Cavite junto a varias galeras (ValdezBubnov, 2017: 239-242).

Pineda realizó un considerable esfuerzo por detallar las dificultades que enfrentaban estas operaciones. La más importante y reveladora era la necesidad de transferir toda la flota, con la excepción de tres unidades, a la isla de Marinduque, debido al crecido gasto de los arrastres de maderas desde las zonas de tala hasta la bahía de Cavite. Este es un indicio inequívoco de una temprana deforestación en las cercanías

22. AGI, FILIPINAS,340, L.3, F.48V-49R.

23. AGI, FILIPINAS, 329, L. 2. 
IVÁN VALDEZ-BUBNOV

LA CONSTRUCCIÓN NAVAL ESPAÑOLA EN EL PACÍFICO SUR: EXPLOTACIÓN LABORAL, RECURSOS MADEREROS Y TRANSFERENCIA INDUSTRIAL ENTRE NUEVA ESPAÑA...

de Manila, lo cual contribuye a explicar la dispersión de los astilleros anteriormente mencionados, así como de la vinculación explícita de determinados pueblos de indios con las zonas de explotación maderera.

La segunda causa de dificultad señalada por Pineda era la escasez de trabajadores indígenas, resultante de recientes incursiones por parte de los musulmanes de Mindanao. El capitán de maestranza indicaba que, en una expedición capitaneada por Juan de Silva contra los holandeses en las Molucas, en 1616, habían muerto más de 700 marineros indígenas, de los cuales más de 200 eran también carpinteros (Valdez-Bubnov, 2017: 242-245).

Ambas consideraciones - la devastación de las forestas y la escasez de trabajadores de astillero - llevaron a Pineda a proponer explícitamente que el Consejo de Indias ordenase al gobernador Alonso Fajardo cancelar la construcción naval en Filipinas, para transferirla al puerto de Cochin, India, donde los navíos saldrían más baratos, muy fuertes, y podrían durar «hasta treinta años». Para ello, sugería que se enviara a la India maestros de construcción, y otros operarios, desde los astilleros filipinos. La propuesta, sin embargo, presentaba también una faceta de interés mercantil, pues Pineda indicaba que, una vez botados al agua, estos buques podían transportar insumos militares, maderas de construcción, y esclavos para la boga de las galeras de Manila, todo lo cual podía obtenerse a muy buen precio en India. Incluso proponía que la marinería fuese reclutada entre las poblaciones musulmanas de esa región (Valdez-Bubnov, 2017: 246)24.

La opinión de Pineda fue compartida por el ya mencionado procurador general de Filipinas, Hernando de los Ríos Coronel, quien, en ese mismo año de 1619, escribió a Felipe III instándole también a ordenar la transferencia de la industria de construcción naval a India. Los motivos de Ríos Coronel eran semejantes a los problemas laborales enunciados por el padre Sánchez y el obispo Salazar: la construcción de navíos en Filipinas había causado grandes gastos a la Real Hacienda y arruinado a los indígenas, debido a que se les debía grandes cantidades de dinero, tanto por concepto de polos como por vandalas, y el rey sería «bien servido, y su conciencia aliviada», si se les liberaba de esas opresiones ${ }^{25}$. Así, el procurador recomendaba que se ordenara a los gobernadores evitar en todo lo posible emplear a los indígenas en cortes de maderas y trabajos de astillero, sobre todo en los períodos coincidentes con cosechas, así como evitar del todo la construcción de galeones en las islas. Como alternativa, sugería comprarlos ya hechos en India, a mucho menor costo.

Ríos Coronel indicó también que los navíos fabricados en India, además de ser incomparablemente más baratos, resultaban mucho más duraderos. Para ello, proponía que el virrey portugués de Goa facilitara la compra de buques completos

24. Sobre el tráfico portugués de esclavos en esta revión véase: Seijas, 2010: 24-25.

25. AGI, FILIPINAS, 340, L.3. 

RECURSOS MADEREROS Y TRANSFERENCIA INDUSTRIAL ENTRE NUEVA ESPAÑA...

en Bengala y Cochin, donde se fabricaban de una «madera incorruptible», y se aparejaban con jarcia trenzada de una planta denominada cayro, la cual consideraba superior en calidad, e inferior en costo, a la jarcia fabricada en Filipinas. Más aún, en una vertiente mercantil semejante a la propuesta por Pineda, Ríos Coronel sugirió también sistematizar la importación de cayro a las Filipinas, con el fin de canalizar las ganancias a la compra de más navíos en la India ${ }^{26}$.

Resulta evidente que tanto Pineda como Ríos Coronel esperaban recibir autorización de la corona para llevar a cabo operaciones mercantiles en India, bajo el pretexto de liberar a la población indígena de Filipinas de los muchos males ocasionados por la construcción naval. También resulta notable la coincidencia en cuanto a la región donde debían construirse o comprarse los buques ${ }^{27}$. Pero los esfuerzos por transferir la construcción naval a India no terminaron aquí. Por Real Cédula de 12 de abril de 1628, el gobernador Juan Niño de Távora (1626-1632), recibió la confirmación de un bando que fijaba las medidas, calidad y precios de las maderas y otros materiales de construcción utilizados en Filipinas ${ }^{28}$. Según fray Diego de Aduarte, en ese mismo año, el gobernador organizó el envío de una embajada a Camboya, con el objetivo explítico de construir navíos en esa región (Aduarte, 1693: 584). Su correspondencia de este periodo, por otra parte, contiene denuncias de las malas cualidades de las maderas usadas en la construcción naval, las cuales, según su testimonio, eran muy pesadas, y su escasa duración era la causa de la corta vida de los navíos fabricados en Cavite.

Significativamente, al año siguiente, Niño de Távora informó al Consejo de Indias sobre sus intenciones de contratar la fábrica de «algunos buques» en India, utilizando la mediación de un comerciante de salitre llamado Felipe Mascareñas. Anticipando que esto significaba liberar a Filipinas de las desastrosas consecuencias sociales de la construcción naval, el gobernador solicitaba que el rey reconociese su gratitud a Mascareñas, para motivarlo en la continuación de estos esfuerzos. El 1 de agosto de 1629, el gobernador informó al Consejo de Indias de la riqueza de los recursos madereros de Camboya, así como de haber recibido autorización para establecer una factoría y un astillero. Su correspondencia indica que se compró un patache en esa región, y se anticipaba con optimismo el resultado de las operaciones de construcción naval. Este primer galeón camboyano se botó al agua en 1632, y

26. AGI, FILIPINAS, 340, L. 3 .

27. Cochin fue sede de la primera factoría fortificada para el tráfico de especias establecida por los portugueses en el subcontinente indio, tras el abandono de su establecimiento original en Calicut, a principios del siglo XVI. Tras haber aprovechado las rivalidades políticas entre los gobernantes de ambas ciudades, los portugueses recibieron permiso para fundar un enclave permanente en Cochin, lo cual, a su vez, les permitió controlar el tráfico de pimienta hacia la región de Malabar (Boxer, 1977: 50).

28. AGI, FILIPINAS, 329, L. 3. 
se envió un patache desde Manila para arreglar su entrega. Según el gobernador, el buque resultó tener dimensiones mayores a las esperadas, pero había salido mucho más barato que cualquier otro fabricado en Filipinas. Sin embargo, como en otros casos semejantes, las indicaciones de bajos costos no iban acompañadas de cifras concretas. En cambio, Niño de Távora enfatizó la «gran diferencia» en la calidad del maderamen de este navío, previendo que duraría muchos años. Esto le permitió expresar la intención de continuar estas operaciones para producir muchos más, lo cual, señalaba, aliviaría el sufrimiento de las poblaciones indígenas de Filipinas ${ }^{29}$. Cabe señalar que un intento simultáneo por retomar las relaciones diplomáticas con Siam no produjo resultados ${ }^{30}$.

Existen importantes indicios de que la idea de construir los galones en India y Camboya se hallaba ampliamente extendida entre las élites del comercio transpacífico durante este período. En efecto, Gerónimo de Bañuelos, en su Tratado del Estado de las Islas Filipinas, impreso en México en 1638, señalaba que los galeones debían construirse de dos puentes corridas y 500 toneladas de porte, y que «será de gran comodidad que sea su fábrica en Camboja, pues se tiene experiencia de quanta ventaja hacen aquellas maderas... a las de Philipinas...». Además, señalaba las ventajas de la madera demoninada angeli o angelies, proveniente de India «que no admite corrupción» (Bañuelos, 1638: 16). Esta idea también fue expresada por el gobernador Sebastián Hurtado de Corcuera (1635-1644), quien, por Real Cédula de 21 de febrero de 1630, recibió órdenes de mantener siempre en los almacenes y astilleros de las islas todas las maderas y pertrechos necesarios para el aderezo de las naos, pues se había tenido noticia de su escasez ${ }^{31}$. Esto, aparentemente, no pudo cumplirse, lo cual, aparentemente, le condujo a plantear nuevamente el proyecto camboyano $^{32}$.

Las noticias sobre este proyecto son más precisas para el período del gobernador Diego Fajardo y Chacón (1644-1653), durante el cual se registraron graves desastres: un terremoto destruyó la ciudad de Manila en 1645, y tuvieron lugar una serie de ataques desde Mindanao que diezmaron a las poblaciones indígenas de Luzón. Según fray Casimiro Díaz, quien reunió de manera póstuma las notas inéditas de fray Gaspar de San Agustín, impresas en 1890, el primer galéon botado por Fajardo fue el San Diego, construido bajo la superintendencia de Pedro de Mendiola, tras cortes madereros bajo la dirección de un capataz, aparentemente musulmán, de nombre Nadir. Estas operaciones requirieron la movilización de 1200 trabajadores cada mes en las provincias de Tondo, Bulacan, Balayan, y Tayabas, con una obra

29. AGI, FILIPINAS, 8, R.1, N.19.

30. AGI, FILIPINAS, 8, R. 1, N. 6.

31. AGI, FILIPINAS, 330, L.4.

32. AGI, FILIPINAS, 200, N. 206; 8, R.1. N 17; R. 3, N. 63; 9, R. 1, N. 13. 
IVÁN VALDEZ-BUBNOV

LA CONSTRUCCIÓN NAVAL ESPAÑOLA EN EL PACÍFICO SUR: EXPLOTACIÓN LABORAL, RECURSOS MADEREROS Y TRANSFERENCIA INDUSTRIAL ENTRE NUEVA ESPAÑA...

de la cual un curioso comentó «había costado al rey 60 mil pesos, y a los nativos 150 mil». Esto provocó una serie de «tumultos e insurrecciones» en el año de 1649 (Díaz, 1890: 542-543).

La correspondencia del gobernador indica que estas dificultades le llevaron a retomar el proyecto de construcción de galeones en Camboya. Existen también indicios de que esto se debió a la recomendación de los jesuitas, quienes poseían amplia experiencia en aquella región. En efecto, según fray Diego de Aduarte, se envió una embajada a Camboya, aparentemente en 1649, bajo la dirección de fray Domingo Coronado, y esa fábrica se frustró tras la muerte del soberano de ese reino, porque su sucesor decidió «cerrar la puerta a la religión» (Aduarte, 1693, vol. II: 454-455). En una carta al Consejo de Indias, el gobernador Fajardo señaló que su motivación para tal empresa había sido la abundancia de hierro y madera de alta calidad en esas regiones, así como de trabajadores especializados en la construcción naval, dispuestos a trabajar a cambio de un salario. Sin embargo, también señaló la constante penuria de las reales cajas de Manila, ocasionada por lo reducido del situado recibido desde Nueva España ${ }^{33}$. Poco después, Fajardo solicitó al virrey de Nueva España que enviara a Filipinas cuatro maestros de construcción naval, los cuales serían después enviados a Camboya para dirigir la fábrica de seis nuevos galeones. El lenguaje utilizado por el gobernador era ambiguo, tal vez deliberadamente, y deja entrever la impresión de que su intención era obtener más recursos monetarios, pues, al mismo tiempo, solicitaba permiso para construir todos los barcos que fuera posible en esa región del sureste asiático ${ }^{34}$.

El proyecto fue puesto en marcha, y dos frailes jesuitas acompañaron a un equipo de constructores de Cavite, a bordo del galeón Nuestra Señora del Rosario, el cual era conocido por ser uno de los buques más potentes construidos en Filipinas. Sin embargo, encalló al llegar a la bocana del río Mekong, perdiéndose del todo. Con grandes trabajos se recuperaron algunos materiales, y se establecieron un campamento y un astillero en la costa adyacente. El soberano local otorgó su permiso para el inicio de las operaciones, tras un pago de 40.000 pesos. Una vez concluido el navío, sin embargo, exigió otros 25.000 para autorizar su entrega a los españoles. Este dinero tuvo que ser enviado por el sucesor de Fajardo, Sabiniano Manrique de Lara (1654-1663) ${ }^{35}$, quien, además, había encontrado una deuda de más de un millón de pesos en la tesorería, la mitad de la cual correspondía a salarios atrasados, y 150.000 a vandalas sin pagar (Prieto: 1984: 23).

El galeón construido en Camboya fue bautizado San Salvador, y tuvo un final desafortunado. En 1655, regresando de Acapulco, fue sorprendido por una tormenta

33. AGI, FILIPINAS, 9, R. 1, N. 6.

34. AGI, FILIPINAS, 31, N. 23.

35. AGI, FILIPINAS, 285, N. 1. 
IVÁN VALDEZ-BUBNOV

LA CONSTRUCCIÓN NAVAL ESPAÑOLA EN EL PACÍFICO SUR: EXPLOTACIÓN LABORAL, RECURSOS MADEREROS Y TRANSFERENCIA INDUSTRIAL ENTRE NUEVA ESPAÑA...

en las cercanías de Boronga, a 80 leguas de Cavite, donde se fue a pique junto con el galeón San Francisco Xavier. Al respecto de este incidente, el citado texto del padre Díaz ofrece la siguiente reflexión, derivada de las notas de fray Gaspar de San Agustín:

¿Qué mayor providencia se puede haber imaginado que remover totalmente los astilleros de Filipinas y fabricar galeones en el reino de Camboja donde se hacen con menos gastos y buenas maderas y sin el inconveniente de las vejaciones a los naturales? Y por nuestras culpas se han experimentado estos remedios más costosos, porque los más de galeones que se han fabricado en Camboja, se han perdido al traerlos acabados a Cavite, sin haberse logrado hacer viaje en ellos, saliendo más costoso el remedio, que el inconveniente de la enfermedad... (Díaz, 1890: 545).

A partir de este incidente, el gobernador Manrique de Lara prohibió la práctica de construir navíos fuera de Filipinas, pero la correspondencia en la que informó al Consejo de Indias de esta medida no presenta ninguna crítica explícita a la calidad de la fábrica del San Salvador.

En ese mismo año, el gobernador ordenó iniciar una nueva campaña de construcción naval en las islas, la cual resultó en la botadura de un nuevo galeón en el astillero de Cavite, para el cual se usaron los herrajes rescatados del pecio del camboyano. Es posible que se trate del galeón San José, echado al agua en $1656^{36}$ junto con una galera para el servicio de las fortificaciones de Ternate (Prieto, 1984: 25. 41). Otro galeón, de dimensiones mayores, el Nuestra Señora de la Concepción, se construyó en diez meses, y fue botado en 1658. En 1660 se inició otra campaña de construcción naval, la cual generó nuevas insurrecciones indígenas en la provincia de Pampanga, donde se dio muerte al alcalde mayor y a otros españoles, siendo finalmente reprimidas «a sangre y fuego» por Francisco de Esteybar. En consecuencia, Manrique de Lara se vio obligado a tomar dinero de los vecinos españoles de Manila, para pagar a los trabajadores indígenas y concluir los trabajos en el astillero de Cavite (Díaz, 1890: 572-586). Es probable que el navío resultante de estas operaciones haya sido el San Sabiniano, botado al agua en 1663. El gobernador también informó de las relaciones diplomáticas con los reinos de Macasar y Manados (Célebes), Tidore (Molucas), Decalonga, y Camboya (Diaz, 1890: 558-560). Al respecto del mantenimiento de las relaciones con el rey de Camboya, Manrique de Lara escribió: «es bárbaro, y poco seguro». Finalmente, informó también del mantenimiento de relaciones comerciales con Tunkin y Siam, pero sin haber formalizado ningún tratado ${ }^{37}$.

El gobernador Diego de Salcedo (1663-1668) intentó retomar el proyecto de construir galeones en Camboya, para lo cual envió a ese reino a Juan de Vergara, así como al capitán Fernando Quintela. Sin embargo, según Gaspar de San Agustín, esta

36. AGI, FILIPINAS, 31, N. 40.

37. AGI, FILIPINAS, 285, N. 1. 
misión no tuvo resultados concretos. También se enviaron embajadas con los mismos propósitos a Banta y Siam (bajo el mando de Don Francisco Enriquez de Losada); y posteriormente a Batavia (bajo el mando de Juan de Zalaeta), con el objetivo específico de comprar anclas para los navíos de mayor porte. Otros oficiales (Juan de Ergueza y Diego de Palencia) también fueron enviados a ese puerto holandés para arreglar la compra de especias, y su envío a Nueva España Sin embargo al menos el primer galeón construido bajo el mandato de Salcedo, el Nuestra Señora de la Concepción, fue construido en Filipinas, bajo la dirección del «gran maestro» Juan Bautista Nicola (Díaz, 1890: 570). Existen noticias de un segundo galeón, construido en la provincia de Albay bajo la dirección de Diego de Arévalo, el cual salió a la Nueva España el 28 de agosto de 1667 (Díaz, 1890: 657). Estos episodios cierran el periodo durante el cual se llevaron a cabo medidas concretas para transferir la construcción naval desde Filipinas a otras regiones del Pacífico sur, proyectos que no serían retomados sino hasta bien entrado el siglo XVIII.

\section{CONCLUSIÓN}

La industria de la construcción naval puede ser considerada como la primera infraestructura material que hizo posible la expansión hispana en el Pacífico sur. Los primeros cronistas de este proceso prestaron particular atención a los recursos náuticos, materiales y humanos de esa región, con miras al posible establecimiento de una nueva industria de construcción naval, independiente del vínculo transatlántico que sostenía a los astilleros americanos, y capaz de aprovechar los recursos humanos, madereros y manufactureros de la cuenca del Pacífico. La ocupación de Filipinas condujo a la creación de nuevos astilleros en ese archipiélago, pero estos, en principio, fueron vistos como una solución transitoria dentro de un proceso de expansión más vasto, dirigido primordialmente en contra de China. El predominio de los astilleros novohispanos fue tan solo superado con la extinción de esta empresa, en función de las razones expresadas por el padre Alonso Sánchez, y tanto el establecimiento de las rutas transpacíficas hacia Nueva España y el Perú, como la posterior expansión a las Molucas, las intervenciones en Indochina y la ocupación de otros archipiélagos, tuvieron como base una nueva industria de construcción naval permanente, constituida por la administración civil, religiosa, y los recursos madereros y humanos de Filipinas, así como su vínculo mercantil y poblacional con las esferas de influencia de China y de Japón. Esta industria, sin embargo, resultó ser expremadamente perniciosa para las poblaciones indígenas, y fue legitimada por el establecimiento de una legislación que censuraba, al mismo tiempo que permitía, la utilización del trabajo forzado. Como resultado, las periódicas campañas de construcción naval en Filipinas generaron un estado de tensión social permanente entre sus poblaciones indígenas, como también entre las chinas y japonesas, lo cual llevo a funcionarios como Hernando de los Ríos Coronel y Sebastián de Pineda a proponer 
IVÁN VALDEZ-BUBNOV

LA CONSTRUCCIÓN NAVAL ESPAÑOLA EN EL PACÍFICO SUR: EXPLOTACIÓN LABORAL, RECURSOS MADEREROS Y TRANSFERENCIA INDUSTRIAL ENTRE NUEVA ESPAÑA...

la transferencia de la industria a otras regiones del sureste asiático, como parte de intrincadas operaciones de naturaleza mercantil, o como recursos de emergencia ante amenazas militares concretas. Esto condujo a una repetida serie de intentos, a lo largo del siglo XVII, por transferir la construcción naval desde Filipinas, a la India, Camboya y Siam, aunque los resultados nunca estuvieron a la altura de las expectativas de las autoridades de Manila. Es posible que los casos de construcción naval fuera de Filipinas durante este período fueran más numerosos de lo que el estado actual de la investigación nos permite afirmar con certeza.

\section{BIBLIOGRAFÍA}

Aduarte, D. de. (1693). Historia de la Provincia del Santo Rosario de Philipinas, Iapon y China. Zaragoza: Domingo Garzón. 2 vols.

Alonso, L. (2001). La inviabilidad de la hacienda asiática. En M. D. Elizalde, J. Fradera y L. Alonso (coords.), Imperios y naciones en el Pacifico (pp. 181-206). Madrid: CSIC.

Alonso, L. (2003). Financing the Empire: The Nature of the Tax in the Philippines, 15651804. Philippine Studies, 51, 63-95.

Alonso L. (2005). Los Señores del Barangay. La Principalía Indígena en las Islas Filipinas, 1565-1789. En M. Bornemann (ed.), El Cacicazgo en Nueva España y Filipinas (pp. 355-406). México: UNAM.

Amaya Palacios S. (2017). Poderío naval en las Indias: las galeras de Cartagena y (15711621). Revista de Estudios en Seguridad Internacional, 3(2), 169-188.

Argensola, B. L. de. (1609). Conquista de las Islas Malucas. Madrid: Alonso Martín.

Arróniz, O. (1980). El despertar científico en América. México. UAM.

Bankoff, G. (2004), «The Tree as the Enemy of Man»: Changing Attitudes to the Forests of the Philippines, 1565-1898. Philippine Studies, 52(3), 320-344.

Bañuelos y Carrillo, G. de. (1638). Tratado del Estado de las Islas Philippinas y de sus conueniencias. México: Bernardo Calderón.

Borah, W. (1954). Early Colonial Trade and Navigation Between Mexico and Peru. Berleley: University of California Press.

Boxer, C. (1969). Portuguese and Spanish projects for the conquest of southeast Asia, Journal of Asian History, 3, 118-136.

Boxer, C. (1977). The Portuguese Seaborne Empire, 1415-1825. Londres: Hutchinson.

Brand, D. (1956). The Development of the Pacific Coast Ports during the Spanish colonial Period in Mexico. En J. Comas, Juan (ed.), Estudios antropológicos publicados en honor al Doctor Manuel Gamio. México: UNAM, 577-591.

Cervera, J. A. (2013). Los planes españoles para conquistar China a través de Nueva España y Centroamérica en el siglo XVI. Cuadernos de Intercambio, 10(12), 207-243.

Cervera, J. A. (2016). ¿Las Molucas o China? Filipinas y los planes para la expansión hispana a Asia Oriental desde la Nueva España en el siglo XVI. En Yuste, C. y G. Pinzón (coords.), A 500 años del hallazgo del Pacífico (pp. 101-124). México: UNAM, 2016. 
IVÁN VALDEZ-BUBNOV

LA CONSTRUCCIÓN NAVAL ESPAÑOLA EN EL PACÍFICO SUR: EXPLOTACIÓN LABORAL, RECURSOS MADEREROS Y TRANSFERENCIA INDUSTRIAL ENTRE NUEVA ESPAÑA...

Chin, J. K. (2019). The junk trade and Hokkien merchant networks in maritime Asia, 1570-1760. En Bentley, T. H. Picturing Commerce in and from the East Asian Maritime Circuits, 1550-1800. Amsterdam: Univeristy Press.

Clayton, L. (1975). Trade and Navigation in the Seventeenth-Century Viceroyalty of Peru. Journal of Latin American Studies, 1975, 7(1), 1-21.

Crailsheim, E. (2014). Las Filipinas, zona fronteriza. En A. Grageda Bustamante (ed.), Pasajes dela historia latinoamericana en una perspectiva global (pp. 133-152). México: Universidad de Sonora.

Cummins, J. y Cushner, N. (1974). Labor in the Colonial Philippines. Philippine Studies, $22,117-203$

Díaz Trechuelo, L. (2001). Filipinas, la gran desconocida (1565-1898). Pamplona: Ediciones de la Universidad de Navarra.

Elizalde, M. D. y X. Huetz de Lemps. (2015). Un singular modelo colonizador: las órdenes religiosas en la administración española de Filipinas, siglos XVI al XIX. Iles i Imperis, 17(3), 185-220.

Escalante, B. de. (1577). Discurso de la navegacion que los Portugueses... Sevilla: Viuda de Alsono Escrivano.

García-Abasolo, A. F. (1982). La expansión mexicana hacia el Pacífico: La primera colonización de Filipinas (1570-1580). Historia Mexicana, 32(1), 55-88.

Garcia Abasolo, A. F. (2011). Los chinos y el modelo colonial español en Filipinas. Cuadernos de Historia Moderna, 10, 223-242.

García-Abasolo, A. (2013). Españoles y chinos en Filipinas. En España, el Atlántico y el Pacífico y otros estudios sobre Extremadura (pp. 9-29). Llerena: Sociedad Extremeña de Historia.

García-Abasolo, A. (2017). Occidente y Asia en las crónicas de Filipinas del siglo XVII. La atracción de China y la acomodación de la Monarquía Hispánica en las antípodas. e-Spania, 28, 1-16.

García-Garrido, M. A. (2016). Desobediencia y conflictos en el clero de las islas Filipinas (1595-1616). Nuevo mundo Mundos Nuevos, CERMA, Débats 2015, 21 p.

García de Palacio, D. (1583). Diálogos militares. México: Pedro Ocharte.

García de Palacio, D. (1587). Instrucción nauthica. México: Pedro Ocharte.

González de Mendoza, J. (1586). Itinerario y compendio de las cosas notables que hay desde España hasta el reyno de la China. Lisboa: San Phelipe El Real.

Hidalgo Nuchera, P. (2001). La recta administración. Primeros tiempos de la colonización bispana en Filipinas: la situación de la población nativa. Madrid: Polifemo.

Hidalgo Nuchera, P. (2009), Encomienda, trabajo y tributo en Filipinas (1570-1608). Madrid: Polifemo.

Iaccarino, U. (2011). The "Galleon System» and Chinese Trade in Manila at the turn of the $16^{\text {th }}$ Century. Ming Qing Yanjiu, 16, 95-125.

León-Portilla, M. (1985). Hernán Cortés y la Mar del Sur. Madrid: Cultura Hispánica. 
IVÁN VALDEZ-BUBNOV

LA CONSTRUCCIÓN NAVAL ESPAÑOLA EN EL PACÍFICO SUR: EXPLOTACIÓN LABORAL, RECURSOS MADEREROS Y TRANSFERENCIA INDUSTRIAL ENTRE NUEVA ESPAÑA...

Machuca, L. (2009). Proyectos oficiales y modos locales de utilización del Istmo de Tehuantepec en la época colonial: historias de desencuentros. En E. Valézquez, E, Leonoard, y O. Hoffmann (eds.), El istmo mexicano: una región inasequible (pp. 68-94). Marsella: IRD.

Mallari, F. (1989) The Spanish Navy in the Philippines, 1589-1787. Philippine Studies, 37(4), 412-439.

Martínez Shaw, C. (2001). La exploración española del Pacífico en los tiempos modernos. En M. D. Elizalde, J. Fradera, y L. Alonso (eds.), Imperios y naciones en el Pacífico (pp. 3-26). Madrid: CSIC.

McCarthy, W. (1995). The Yards at Cavite; Shipbuilding in early Colonial Times. International Journal of Maritime History, 7(9), 149-162.

Morga, A. de. (1890). Sucesos de las Islas Filipinas. Edición de José Rizal. París: Garnier.

Ollé, M. (2002). La empresa de China. Barcelona: Acantilado.

Ollé, M. (2013). Domingo de Salazar: primer obispo de Manila y defensor de los pobladores de las islas Filipinas. CIEHL, 19, 43-50.

Palanco. F. (2004). Resistencia y rebelión indígena en Filipinas durante los primeros cien años de soberanía española (1565-1665). En Cabrero, L. (ed.), España y el Pacífico (tomo II, pp. 71-98). Madrid: SECC.

Peterson, A. (2014). Making the first Global Trade Route: The Southeast Asian Foundations of the Acapulco Manila Galleon Trade (1519-1650). Manoa: University of Hawaii.

Phelan, J. L. (1959). The Hispanization of the Philippines. Madison: The University of Wisconsin Press.

Pinzón Ríos, G. (2014). Desde tierra y hacia el horizonte marítimo. Una reflexión sobre la relevancia de los establecimientos portuarios del Pacífico novohispano. México y la Cuenca del Pacífico, Año 17, núm. 50, 67-21.

Pizano y Saucedo, C. (1964). El puerto de navidad y la expedición de Legazpi, Historia mexicana, 14(2), 227-249.

Pizano y Saucedo, C. (1964). Jalisco en la conquista de las Filipinas: Barra de Navidad y la expedición de López de Legazpi. México: Sociedad Mexicana de Geografía y Estadística.

Prieto, A. M. (1984). Filipinas durante el gobierno de Manrique de Lara, 1653-1663. Córdoba: CSIC.

Radell, D. R. y Parsons, J. (1971). El Realejo: A Forgotten Colonial Port and Shipbuilding Center in Nicaragua. The Hispanic American Historical Review, 51, 295-312.

Rodao, F. (1997). Españoles en Siam. Madrid: CSIC.

Rodríguez Castillo, N. (2017). Las galeras en Filipinas: guerra, comercio y disciplinamiento social (1580-1650). Historia Social, 87, 149-166.

Ruiz-Stovel, G. (2009). Chinese Merchants, Silver Galleons, and Ethnic Violence in Spanish Manila, 1603-1686. México y la Cuenca del Pacífico, 12(36), 47-63.

Díaz, Casimiro. (1890). Conquista de las Islas Philippinas. Valladolid: Luis de Gaviria.

San Antonio, G. de. (1604). Breve y verdadera relación de los sucesos del Reyno de Camboxa. Valladolid: Pedro Lasso. 
IVÁN VALDEZ-BUBNOV

LA CONSTRUCCIÓN NAVAL ESPAÑOLA EN EL PACÍFICO SUR: EXPLOTACIÓN LABORAL, RECURSOS MADEREROS Y TRANSFERENCIA INDUSTRIAL ENTRE NUEVA ESPAÑA...

Sánchez Gómez, L. A. (2004). Las élites nativas y la construcción colonial de Filipinas (1565-1789). En L. Cabrero (ed.), España y el Pacífico (vol. II, pp. 37-70). Madrid: Sociedad Estatal de Conmemoraciones Culturales.

Sánchez Gómez, L. A. (2010). Gobierno y administración del territorio en Filipinas (15651898). En S. Bernabéu Albert (ed.), Poblar la inmensidad: sociedades, conflictividady representación en los márgenes del Imperio Hispánico (siglos XV-XIX) (pp. 465-532). Barcelona: Ediciones Rubeo, CSIC..

Sales-Colin Kortajerena, O. (2011). Polistas y arquitectura naval: una polémica contra los recursos de la tierra filipina durante el siglo XVII. Revista de Historia Naval, 23(122), 59-76.

San Ignacio, V. (2001). The State of the Philippine Economy during the Spanish Period. En M. D. Elizalde, J. Fradera, y L. Alonso (eds.), Imperios y naciones en el Pacífico (pp. 381-394). Madrid: CSIC.

Scott, W. H. (1995). Barangay: Sixteenth Century Philippine Culture and Society. Quezon City: Ateneo de Manila University Press.

Seijas, T. (2008). The Portuguese Slave Trade to Spanish Manila: 1580-1640. Itinerario, $32,19-38$.

Sluiter, E. (1998) The gold and silver of Spanish America, c. 1572-1648: Tables showing bullion declared for taxation in colonial royal treasuries, remittances to Spain, and expenditures for defense of empire. Berkeley: University of Californa Press.

Sola García, D. (2016) Juan González de Mendoza y la Historia del Gran Reino de la China: la construcción del relato sinológico desde la Europa del Quinientos. Revista Estudios, (32), I.

Subrahmanyam, S. (2007). Holding the World in Balance: The Connected Histories of the Iberian Overseas Empires, 1500-1640. The American Historical Review, 112(5), 1359-1385.

Tellechea Idígoras, J. I. (1989). Martín Ignacio de Loyola. Viaje alrdedor del mundo. Madrid: s/e.

Valdez-Bubnov, I. (2017) Comercio, guerra y tecnología: la construcción naval para la carrera de Filipinas (1577-1757). En A, J. Rodríguez Hernández, A. J. Vozmediano y J. A. Sánchez Belén (eds.), Comercio, guerra y finanzas en una época en transición (siglos XVII-XVIII) (pp. 225-270). Valladolid: Castilla Ediciones.

Valdez-Bubnov, I. (2019a). Las islas Filipinas y la etapa formativa de la construcción naval española en Asia, (1519-1657). Obradoiro de Historia Moderna, 28, 29-54.

Valdez-Bubnov, I. (2019b). Crown, trade, church and indigenous societies: The functioning of the Spanish shipbuilding industry in the Philippines, 1571-1816. International Journal of Maritime History, 31(3), 559-573.

Wing, John T. (2015). Roots of Empire. Forests and State Power in Early Modern Spain, c. 1500-1750. Leiden-Boston: Brill.

Yuste, C. (1984). El comercio de Nueva España con Filipinas, 1590-1785. México: INAH. 